\title{
NEUROLINGUÍSTICA DISCURSIVA: CONTRIBUIÇÕES PARA DISCUTIR A RELAÇÃO ENTRE LINGUAGEM E POBREZA
}

\author{
ELAINE CRISTINA DE OLIVEIRA ${ }^{1}$
}

(UFBA)
MARCUS VINICIUS BORGES OLIVEIRA ${ }^{2}$
(UFBA)

\begin{abstract}
RESUMO: Este artigo tem como proposta discutir as contribuições da Neurolinguística Discursiva para repensarmos os efeitos que perspectivas estritamente biológicas têm construído sobre a relação entre linguagem e pobreza. Analisamos criticamente como a pobreza tem sido interpretada como sinal de fracasso, ou mesmo como doença (distúrbios de linguagem e cognitivos, por exemplo), em vários estudos, principalmente nas neurociências. No que diz respeito à linguagem, os procedimentos descontextualizados objetificam os sujeitos, lhes retiram sua voz, seus discursos, desconsideram violentamente as diferentes práticas de linguagem nas quais estão inseridos e transformam dificuldades, por vezes próprias da exclusão social, em déficits. Apontamos como os estudos da ND, especialmente aqueles desenvolvidos por Maria Irma Hadler Coudry desde seu trabalho pioneiro em Diário de Narciso: discurso e afasia, podem contribuir para desconstruir visões preconceituosas sobre linguagem, sujeito e pobreza.
\end{abstract}

Palavras-chave: neurolinguística discursiva; linguagem; pobreza

ABSTRACT: This paper aims to discuss the contributions of Discursive Neurolinguistics (ND) to think over the effects of strictly biological perspectives on the relationship between language and poverty. We critically analyze how poverty has been interpreted as a sign of failure, or even as a disease (language and cognitive disorders, for example), in several studies, mainly within neurosciences. Regarding language, the decontextualized procedures objectify subjects, withdraw their voice and their discourses, violently disregard the different language practices in which they are inserted and transform difficulties, that are often consequences of social exclusion, in deficits. We also point out how ND studies, especially those developed by Maria Irma Hadler Coudry, since her pioneer work Diário de Narciso: discurso e afasia, can contribute to deconstruct preconceived views on language, subject and poverty.

Keywords: discursive neurolinguistics; language; poverty.

1 Professora do Departamento de Fonoaudiologia da Universidade Federal da Bahia. elaineoliveira1009@gmail.com

${ }^{2}$ Professor do Departamento de Fonoaudiologia da Universidade Federal da Bahia. marcus. oliveira.fono@gmail.com 


\section{INTRODUÇ̃̃O}

Este artigo propõe uma reflexão crítica sobre como a relação entre linguagem e pobreza $a^{3}$ tem sido apresentada em estudos das Neurociências ou, mais especificamente, da Neuropsicologia de cunho clínico e/ou pedagógico. Para tanto, trazemos uma outra perspectiva sobre o tema, a partir dos pressupostos teóricos e metodológicos da Neurolinguística Discursiva (doravante ND), que acreditamos ser o lugar adequado de onde podemos lançar este olhar.

É necessário apontar, primeiramente, que desde o seu surgimento, em 1986 com a Tese de Doutorado de Maria Irma Hadler Coudry e, posteriormente, com o livro homônimo «Diário de Narciso: discurso e afasia», em 1988 -, a ND formula uma crítica à maneira reducionista como a linguagem vinha sendo estudada na afasia (e em outras alterações de linguagem), crítica essa que se estende para o modo como se relacionam sujeito, cérebro e linguagem nesse contexto.

Nos seus fundamentos mais básicos, Coudry (1988, p. XVIII) afirma que não utiliza uma metodologia quantitativa nos exames dos dados e que lhe interessa menos a afasia como um objeto de investigação e mais a prática de como o sujeito se reconstitui e como reconstrói sua linguagem. Fica claro, desde então, que temos aí uma ética que fundamenta as escolhas da autora, que orienta uma clínica voltada para o descobrimento mútuo, para a construção conjunta, não impositiva.

Pode parecer estranho nos basearmos em um trabalho inicialmente concebido sobre as afasias para subsidiar uma análise crítica sobre a relação entre Linguagem e Pobreza. Neste sentido, dois esclarecimentos são importantes. O primeiro é que a própria ND não se reduz ao estudo das afasias, pois vem ampliando seu escopo sempre que as questões sobre cérebro, mente e linguagem estão implicadas. Mais recentemente, acompanhamos Bordin ao dizer que «interessa à ND estudar, tanto na criança quanto no adulto, a relação entre língua, linguagem, cérebro/mente, praxia/corpo, percepção, pensamento, memória, em contextos da normalidade e da patologia, compreendendo o que caracteriza uma e outra» (BORDIN, 2006, p. 12).

O segundo esclarecimento, mais importante, é de que também seguimos o princípio ético que nos conduz a valorizar mais os sujeitos e suas relações do que a pobreza em si. É lugar comum falar da pobreza como um determinante inescapável, enclausurando os sujeitos como se estes já estivessem completos, previamente doentes, potencialmente acabados, sem nenhum horizonte de possibilidades (BAKHTIN, 1997). De acordo com Yazbek:

Abordar aqueles que socialmente são constituídos como pobres é penetrar num universo de dimensões insuspeitadas. Universo marcado pela subalternidade, pela revolta silenciosa, pela humilhação e fadiga, pela crença na felicidade das gerações futuras, pela alienação e resistência e, sobretudo, pelas estratégias para melhor sobreviver, apesar de tudo (YAZBEK, 2012, p. 292).

\footnotetext{
${ }^{3}$ Parte das reflexões desenvolvidas neste artigo tiveram início no curso de especialização "Educação, Pobreza e Desigualdade Social, que ocorreu na Faculdade de Educação da Universidade Federal da Bahia (2016-2017), em que participamos como Coordenadora e Professor de Pensamento Crítico, respectivamente.
} 
Quando se trata da linguagem, como veremos adiante, esses sujeitos têm sido avaliados por meio de protocolos de desempenho que só podem lhes confirmar um lugar prévio, já que são produzidos dentro de uma concepção científica de base excludente, repleta de preconceitos e estigmatizações que retiram o sujeito de sua historicidade.

Tal como Coudry, consideramos o sujeito como "incompleto, imaturo, e ao mesmo tempo múltiplo: ao mesmo tempo social, histórico, psicológico e psicanalítico, biológico, linguístico" (COUDRY, 1988, p. 67). Também recorremos a Franchi (1988), um dos principais autores da obra de Coudry, para respaldar a reflexão sobre tal incompletude e sobre o trabalho implicado na produção de linguagem pelos sujeitos. É dentro desse escopo que a linguagem pode ser entendida, como

[...] um trabalho social, histórico, que constitui não somente os recursos expressivos das línguas naturais e um modo próprio de representar a realidade, mas ainda as 'regras' de utilização das expressões em determinadas situações de fato e em determinadas condições de uso (FRANCHI, 1988, p. XIV).

Para compreender as relações entre linguagem e pobreza, partimos então de outro campo, que não se definirá pela "busca do que falta" aos sujeitos e discutiremos as contribuições da ND para repensarmos as relações que uma perspectiva medicalizante tem construído.

\section{POBREZA, ESTIGMATIZAÇÃO E PRECONCEITO}

De acordo com Yazbek, "a pobreza é parte de nossa experiência diária" (YAZBEK, 2012, p. 290); o que faz com que todos nós tenhamos construída uma noção do que significa ser pobre. No senso comum, talvez a primeira coisa que nos venha à mente seja a relação com a falta de dinheiro, de comida, de casa etc. Deste ponto de vista, a pobreza parece ser um objeto transparente e de fácil categorização, contudo, se buscássemos defini-la como objeto de investigação, ou mesmo definir os seus parâmetros, perceberíamos a sua complexidade.

A pobreza não pode ser encarada como «falta de» algo; como negação; nem mesmo ser definida apenas a partir de parâmetros socioeconômicos. Entretanto, é importante mencionar que, mesmo em determinadas concepções neoliberais, que vão além da concepção de renda como único fator constitutivo da pobreza, esta pode se configurar ainda como ausência de capacidades, o que, a nosso ver, ignora as raízes sócio-históricas que a envolvem.

Para Yazbek (2012), a pobreza é ampla, uma categoria multidimensional que supõe gradações; que não se caracteriza apenas pela inacessibilidade aos bens, mas que se traduz como uma forma de inserção social em que se negam direitos, oportunidades, informações, tecnologias. De acordo com a autora, a pobreza: 
Usualmente vem sendo medida por meio de indicadores de renda e emprego, ao lado do usufruto de recursos sociais que interferem na determinação do padrão de vida, tais como saúde, educação, transporte, moradia, aposentadoria e pensões, entre outros. Os critérios, ainda que não homogêneos e marcados pela dimensão de renda, acabam por convergir na definição de que são pobres aqueles que, de modo temporário ou permanente, não têm acesso a um mínimo de bens e recursos, sendo, portanto, excluídos, em graus diferenciados, da riqueza social (YAZBEK, 2009 apud YAZBEK, 2012, pp. 290-291).

É importante perceber que a pobreza tem causas sociais e econômicas que a determinam. Não podemos nos abster de compreender seu lugar em um campo de contradições que emerge historicamente da desigualdade. É proveniente de um modo de organização social que tem base excludente, não por acaso, mas pela sua própria estrutura e funcionamento, não sendo, portanto, um fenômeno natural. É desse ponto de vista que podemos entender como as características que desenham um perfil social, étnico, racial, de gênero estão profundamente demarcadas pela história do Brasil.

Destituídos dessa compreensão histórica e social, os pobres são responsabilizados pela própria pobreza e pelo desemprego, por exemplo, como se lhes faltassem habilidades de competitividade no mundo ou como se não quisessem trabalhar. Daí surgem preconceitos vigentes, argumentos moralistas que equiparam a reprodução de desigualdades com preguiça, indolência etc.

Do ponto de vista da linguagem, o senso comum dirá que os pobres falam errado, não argumentam, têm pouco a dizer. Para entender como esse mecanismo de exclusão se perfaz na linguagem, temos que considerar que dentro de uma mesma comunidade coexistem variedades linguísticas que refletem a hierarquia social (ALCKMIM, 2001) dos falantes, ou, como diria Gnerre (1985), que uma variedade linguística vale o que os seus falantes valem na sociedade.

De acordo com Novaes-Pinto (2008), equívocos que respaldam a visão de uma língua única e correta geram preconceitos que também atravessam o entendimento clínico e científico do estudo das patologias que podem acometer a linguagem. A esse propósito, é importante ressaltar que, por vezes, até variações sociolinguísticas podem ser interpretadas de maneira equivocada, clinicamente, como desvios de natureza fonológica. ${ }^{4}$

\section{LINGUAGEM E POBREZA NAS NEUROCIÊNCIAS}

Vários estudos (conferir, por exemplo, GUIMARÃES, 2012; ENGEL DE ABREU et al, 2015; GARCIA, 2016; LIPINA e POSNER, 2012) no campo das neurociências têm se dedicado a estabelecer relações entre o nível socioeconômico de uma população e aspectos denominados, nesse campo, como sendo de natureza cognitiva, de linguagem e educacionais.

\footnotetext{
${ }^{4}$ Não raro vemos nos prontuários fonoaudiológicos, na nossa prática clínica, palavras como "pobrema", "broco", "bicicreta" sendo analisadas como se fossem desvios fonológicos, sem a preocupação de buscar compreender o contexto sociocultural em que os sujeitos estão inseridos.
} 
Guimarães refere que "o nível socioeconômico tem sido fortemente relacionado com habilidades de cognição geral e desempenho acadêmico" (GUIMARÃES, 2012, p. 2); que a pobreza influencia não só a saúde geral, mas também a saúde mental, sendo que "indivíduos com nível social mais baixo tendem a apresentar maiores taxas de transtornos psiquiátricos" (GUIMARÃES, op. cit.). Para a autora:

Já identificamos que as diferenças de renda têm influência sobre habilidades cognitivas. No entanto, dificilmente fornecer dinheiro a uma família será suficiente para mudar toda a estrutura familiar em prol do melhor desenvolvimento das crianças. Da mesma forma, dar benefícios tardios a crianças que nasceram em um ambiente mais pobre, como acontece no caso das cotas, apesar de poder ajudá-las ao inseri-las em um ambiente cognitivamente enriquecido, não será suficiente para suprir todos os desfalques que esta teve durante a infância (GUIMARÃES, 2012, p.3).

Nota-se neste estudo que, além de estabelecer um vínculo entre pobreza e déficits cognitivos, a autora aponta que as causas e as consequências do suposto déficit sobre "as habilidades cognitivas" ocorrem na infância e seriam insuperáveis, mesmo com a inserção do sujeito no que a autora chama de "ambiente cognitivamente enriquecido".

Ao longo do estudo, Guimarães (2012) afirma que se déficits cognitivos não forem "tratados" logo de início, jamais serão reparados na idade adulta, mesmo com o apoio de políticas públicas educacionais, como é o caso das cotas. Notase que se o suposto déficit cognitivo não for superado na infância, jamais o será, ou seja, este sujeito estará sempre um passo atrás em relação àquele que nasceu numa condição socioeconômica superior. Observa-se, no trecho citado acima, que o problema estrutural da pobreza é o suposto déficit cognitivo e não o modelo capitalista de base excludente no qual vivemos.

Outro estudo que destaca a relação entre o desenvolvimento da linguagem e o nível socioeconômico do indivíduo é o de Engel de Abreu et al (2015), no qual os autores relatam que como o aprendizado da linguagem ocorre por meio das interações sociais, não é surpresa "que a quantidade e o tipo de palavras usadas nos momentos de interlocução com jovens e crianças influenciem o seu desenvolvimento" (ENGEL DE ABREU et al, p. 2). Para os autores:

As famílias de níveis socioeconômicos mais baixos tendem a usar palavras e sentenças em menor quantidade e complexidade do que as famílias com maior renda, o que, em parte, explica porque as crianças das camadas mais pobres tendem a desenvolver mais lentamente a linguagem (Hoff, 2003). Vale ressaltar que a linguagem é a ferramenta que os pais e professores usam para transferir conhecimento e habilidades, exercendo, desta forma, uma influência crucial no desempenho escolar das crianças (ENGEL DE ABREU et al, 2015, p. 15).

A relação que estudos como o de Engel de Abreu et al. estabelecem entre língua/linguagem e pobreza é, do ponto de vista linguístico, no mínimo, preconceituosa e pautada no mito de uma unidade linguística que, na verdade, não existe. 
A afirmação de que "as famílias de níveis socioeconômicos mais baixos tendem a usar palavras e sentenças em menor quantidade e complexidade do que as famílias com maior renda" (ENGEL DE ABREU et al, 2015, p. 15) não tem fundamento na ciência linguística, sendo puro preconceito.

Para Bagno, embora o português seja falado pela grande maioria da população brasileira, esta língua apresenta um alto grau de diversidade e de variabilidade tanto por causa da grande extensão territorial do país (fato que provoca diferenças regionais importantes), quanto "da trágica injustiça social que faz do Brasil o segundo país com a pior distribuição de renda em todo o mundo" (BAGNO, 1999, p. 16). Para o autor:

São essas graves diferenças de status social que explicam a existência, em nosso país, de um verdadeiro abismo linguístico entre os falantes das variedades não-padrão do português brasileiro - que são a maioria de nossa população - e os falantes da (suposta) variedade culta, em geral mal definida, que é a língua ensinada na escola (BAGNO, 1999, p. 16).

A respeito do modo como o preconceito e a estigmatização são transferidos para o plano linguístico, especificamente para as variedades linguísticas consideradas não-padrão, Bagno e Rangel (2005) ressaltam que esses preconceitos são, no fundo, sociais.

Para Bagno e Rangel (2005, p. 78), pessoas pobres e de origem rural, que não tiveram acesso ao direito de uma educação formal e procedem de uma região considerada atrasada, teriam sua maneira de falar a língua considerada 'pobre', 'tosca', 'inculta', 'atrasada' etc, ou seja, tal atraso linguístico seria uma decorrência 'natural' da pobreza e da falta de inserção em um ensino formal. Os autores ressaltam ainda que

[...] um dos princípios norteadores de toda a ciência linguística moderna é o de que todas as línguas e todas as variedades de língua se equivalem no que diz respeito a suas complexidades estruturais e a seus recursos expressivos, não existindo, portanto, línguas/variedades "primitivas", nem línguas/variedades "inferiores" a outras, supostamente mais "desenvolvidas". Assim, a simples afirmação de que um indivíduo "fala errado" já constitui um atentado aos seus direitos linguísticos (BAGNO e RANGEL, 2005, p. 78).

Engel de Abreu et al. ainda mencionam em seu estudo que conhecer quais as consequências que um "ambiente empobrecido" provoca no aspecto cognitivo da criança é importante, "pois fornece uma base cientificamente fundamentada a programas de intervenção que visam a auxiliar crianças vulneráveis e em iminente risco de insucesso escolar" (ENGEL DE ABREU et al, 2015.p. 5). Os autores, após realizarem uma bateria de testes com crianças de vários níveis socioeconômicos, matriculadas em escolas públicas e privadas, observaram que

[...] crianças brasileiras crescendo em situação de pobreza têm as funções executivas e as habilidades de linguagem muito menos desenvolvidas quando comparadas a crianças vivendo em realidades economicamente mais favorecidas. Esta pode ser uma parte da razão que explica o fraco desempenho acadêmico apresentado por tais crianças. Os resultados indicam também que os diferentes tipos de escolas frequentadas por crianças de menor e maior nível socioeconômico podem afetar o potencial de aprendizagem. Poucas oportunidades de aprendizagem, tanto em casa quanto na escola, colocam as crianças pertencentes às classes socioeconômicas mais baixas em duplo risco (ENGEL DE ABREU et al, p. 29). 
No que se refere à avaliação da língua/linguagem por meio de testes, há muito tempo a ND vem discutindo as suas implicações. Nas suas primeiras publicações (COUDRY E POSSENTI, 1983; COUDRY, 1988; COUDRY E SCARPA, 1991), a autora estabelece algumas críticas a respeito dos testes "padrão", muito utilizados nas neurociências (seja na prática clínica ou para a pesquisa acadêmica). Coudry (1988) faz uma crítica à aplicação de testes padronizados (como os utilizados nos estudos de Engel de Abreu et al, 2015) como método de avaliação da linguagem. Para a autora, os testes são tarefas descontextualizadas e calcadas, em sua maioria, em unidades linguísticas menores que as frases ou reduzidas a palavras isoladas. Além disso, essas tarefas simulam situações artificiais para uma suposta atividade linguística. Para a autora, nesses testes predominam tarefas metalinguísticas, nas quais o sujeito é privado da atividade epilinguística e reflexiva, indispensável à construção e reconstrução da linguagem. Priva-se, ainda, o avaliador de conhecer de que forma o sujeito elabora as hipóteses sobre a estruturação e uso da linguagem. Coudry (1988) ressalta, também, que as tarefas propostas - nomear, definir, listar, repetir etc. - correspondem a exercícios fundados na língua escrita, com um forte compromisso escolar, sendo que muitas vezes as tarefas são reduzidas a técnicas de abordagem necessárias apenas para a descrição acadêmica de uma patologia.

Do ponto de vista da ND, há uma relação estreita entre cérebro e linguagem, fundamentada na ideia de que não se podem dissociar funções cognitivas - como memória e percepção - da atividade discursiva. Tendo por base a concepção luriana do funcionamento da atividade cerebral, para a ND, linguagem e cérebro funcionam como um sistema dinâmico, integrativo e histórico (COUDRY, 2002; COUDRY e FREIRE, 2007).

É importante destacar que, para Coudry e Freire (2005; 2007), a concepção de cérebro e de linguagem assumida pela ND não permite uma divisão estrita entre o que é da ordem do normal e do patológico, fato que não nos possibilita negar a existência da patologia, pois "sempre que o aparelho cerebral for privado - por lesões congênitas e/ou adquiridas - de suas estruturas e funções, a patologia se estabelece" (COUDRY e FREIRE, 2005, p. 13). No entanto, baseadas, também, nos estudos de Foucault (1969) e Canguilhem (1995), as autoras observam que não se pode adotar como critério diferenciador de normalidade/patologia um funcionamento cerebral - e, acrescentemos, do sistema linguístico - médio e regular, desprovido de sentido, a-histórico e idealizado, tal como pretendido por estudos da área das neurociências, como os mencionados anteriormente.

De acordo com Novaes Pinto (2012), uma questão central nos estudos neuropsicológicos é a prevalência de modelos sobre o funcionamento cerebral que excluem de seu escopo as marcas da subjetividade. Para a autora, isso ocorre tanto na clínica quanto na escola, seja pela higienização das variáveis individuais em vias da objetividade científica ou no ensino uniforme e homogeneizado de todos os alunos, a despeito de toda sua diversidade.

Novaes Pinto (1999) questiona o caráter redutor das baterias de testes que avaliam dificuldades como déficits e perdas e as contrapõe com situações de uso efetivo da linguagem, o que permite compreender melhor o funcionamento da linguagem e a relação entre o normal e patológico. A autora, também fundamentada em Canguilhem (1995), questiona o estatuto do normal enquanto ideal, formulado sempre de acordo com a variedade normativa da língua. 
Apontamos aqui, em consonância com as autoras supracitadas, nossa preocupação com a utilização de baterias de testes que se baseiam em modelos que desconsideram as situações efetivas da linguagem, e com isso, não são capazes de avaliar o trabalho conjunto, dialógico, que se realiza com e sobre a linguagem.

Estudos como os de Guimarães (2012), Engel de Abreu et al (2015) e Andrade et al (2005) que relatam que o baixo nível socioeconômico podem resultar em "prejuízos para solução de problemas, linguagem, memória e habilidades sociais" (ANDRADE et al, 2005, p. 607) reforçam a "Teoria da Carência Cultural", a qual, segundo Patto (1997), é portadora de todo tipo de estereótipos e preconceitos sociais sobre os pobres. Essa teoria, gerada nos anos 60 nos Estados Unidos da América, argumenta que o fracasso escolar ocorre devido à deficiência ou privação de determinados elementos culturais do aluno em função das suas precárias condições de vida, novamente culpabilizando o sujeito, desconsiderando os determinantes sócio-históricos que estruturam a pobreza.

É importante ressaltar que uma certa concepção neoliberal do que é a pobreza, destituída dos determinantes sociais e históricos que a constituem, se encaixa perfeitamente à ideia de que o homem pode ser medido e quantificado.

Por exemplo, se tomarmos a análise realizada por Ugá sobre as formulações de política social do Banco Mundial, perceberemos que a pobreza é definida, no relatório de 1990, como como incapacidade de atingir um padrão de vida mínimo. Para a autora, sobre o mundo do trabalho, no referido relatório está implícito que:

De um lado, estão os indivíduos que conseguem atuar no mercado - que seria o mecanismo de funcionamento "mais eficiente" da sociedade - e, de outro, estariam aqueles incapazes de integrar-se aos mercados - os pobres -, dos quais o Estado deve cuidar, por meio de suas políticas sociais residuais e focalizadas (UGÁ, 2004, p. 58).

Dentro desta concepção de pobreza enquanto incapacidade de pertencer ao mundo do trabalho, entre mecanismos de sua superação, estaria o aumento do capital humano, conforme podemos ver no trecho abaixo:

[...] o investimento em capital humano é um dos meios mais importantes para reduzir a pobreza, pois o principal bem dos pobres é o tempo para trabalhar. A educação aumenta a produtividade deste bem. O resultado, no nível individual, é uma renda mais alta, como demonstram muitos estudos" (BANCO MUNDIAL, 1990, p. 85, Apud UGÁ, 2004, p. 59, grifo nosso).

A ideia subjacente a essa concepção de pobreza é a de que ela pode ser superada qualificando o indivíduo pobre para o mercado de trabalho, tornando-o mais competitivo. Mesmo na análise de relatórios subsequentes, quando a autora reflete sobre a mudança do conceito de capital humano para o de capacidade humana, criticamente conclui que o Estado se limitaria a aumentar as capacidades humanas dos pobres, não se constituindo como um Estado de direito, mas de caridade, necessário somente para capacitar os pobres para que, posteriormente, individualmente, busquem seus lugares no mercado, o que reflete o esvaziamento da noção de cidadania e de universalidade de direitos. 
Nesse sentido, é essencial pensar no paradigma científico de uma neurociência que, estando alheia aos aspectos sociais e históricos estruturantes da realidade dos sujeitos, tem considerado a pobreza como o resultado de uma incapacidade ou inabilidade cognitiva adquirida principalmente na infância, materializada em transtornos de leitura, de escrita, em rótulos como dislexia, TDAH, TOD etc. Dentro da concepção neoliberal de pobreza que expomos acima, uma clínica pautada no ajuste de capacidades cognitiva serviria, no fundo, para garantir um sujeito apto para alcançar um melhor lugar no mercado de trabalho. No que diz respeito à linguagem, temos a promessa de uma neurociência que instrumentaliza métodos educativos homogeneizantes e eficazes, pautados no funcionamento modular de um cérebro ideal, sem refletir propriamente o que significa educar dentro de contextos específicos e complexos como o da pobreza.

\section{CONSIDERAÇÕES FINAIS}

Neste artigo, buscamos analisar criticamente como a pobreza tem sido interpretada em sua relação com o fracasso, como incapacidade, ou mesmo como doença. No que diz respeito à linguagem, os procedimentos descontextualizados objetificam os sujeitos, lhes retiram sua voz, seus discursos, desconsideram violentamente as diferentes práticas de linguagem nas quais estão inseridos e transformam dificuldades, por vezes próprias da exclusão social, em déficits.

Ao trabalhar com a temática da pobreza, devemos sempre ter em mente que não podemos objetificá-la. De acordo com Bakhtin (1997), o que difere as ciências humanas das demais ciências é o fato de que o homem não pode jamais ser estudado como um objeto mudo e passível de ser descrito. No caso do homem, não falamos sobre ele, como se o mesmo não tivesse o que dizer, mas conversamos com ele.

O que nos motivou a fazer esta análise está nos princípios básicos da Neurolinguística Discursiva, desde quando Coudry questionou a forma como as "verdades" científicas tinham se estabelecido no campo das afasias. Da mesma forma, com relação à pobreza, questionamos análises que não valorizam a relação entre sujeito e a linguagem dentro do contexto histórico social de que fazem parte.

\section{REFERÊNCIAS}

ALCKMIM, T. Sociolinguística In: MUSSALIN \& BENTES (Orgs). Introdução à Linguística: domínios e fronteiras. São Paulo: Ed. Cortez, 2001.

ANDRADE, S. A. et al. Ambiente familiar e desenvolvimento cognitivo infantil: uma abordagem epidemiológica. Rev. Saúde Pública, São Paulo, v. 39, n. 4, pp. 606-611, Aug. 2005. Disponível em: <http://www.scielo.br/scielo.php?script=sci_arttext\&pid=S0034-89102005000400014\&ln $\mathrm{g}=\mathrm{en} \& \mathrm{nrm}=$ iso $>$. Acessado em: 11 de junho de 2017 .

BAGNO, M. Preconceito linguístico- o que é, como se faz. Loyola: São Paulo, 1999. 
BAGNO, M.; RANGEL, E. O. Tarefas da educação linguística no Brasil. Revista Brasileira de Linguística Aplicada, 5 (1):63-81, 2005.

BAKHTIN, M. Estética da Criação Verbal. 2. ed. São Paulo: Martins Fontes, [1979] 1997.

BORDIN, S. M. S. Fale com ele: um estudo neurolinguístico do autismo. 2006. $129 \mathrm{f}$. (Dissertação mestrado em Linguística) - Instituto de Estudos da Linguagem, UNICAMP, Campinas, 2006.

CANGUILHEM, G. O Normal e o Patológico. Rio de Janeiro: Forense Universitária, 1995.

COUDRY, M. I. H. Diário de Narciso: discurso e afasia. 1. ed. São Paulo: Martins Fontes, 1988.

COUDRY, M. I. H. Linguagem e afasia: uma abordagem discursiva da neurolinguística. Cadernos de Estudos Linguísticos. (UNICAMP), v. 42, n.42, pp. 99-129, 2002.

COUDRY, M. I. H.; FREIRE, F. M. P. O trabalho do cérebro e da linguagem: a vida e a sala de aula. 1. ed. Campinas (SP): CEFIEL/UNICAMP, 2005.

COUDRY, M. I. H.; FREIRE, F. M. P. Neurolinguística discursiva: teorização e prática clínica. Caminhos da neurolinguística. 2007

COUDRY, M. I. H.; SCARPA, E. M. De como a avaliação da linguagem contribui para inaugurar o déficit. IN: ROGO, R. H. R., CUNHA, M. C., GARCIA, A. L. M. Fonoaudiologia \& Linguística, São Paulo: Educ, 83-93, 1991.

COUDRY, M.I.H; POSSENTI, S. Avaliar Discursos Patológicos. Cadernos de Estudos Linguísticos (UNICAMP), v. 5, pp. 99-109, 1983.

ENGEL DE ABREU et al. A Pobreza e a Mente: Perspectiva da Ciência Cognitiva. Walferdange, Luxembourg: The University of Luxembourg, 2015.

FRANCHI, C. Prefácio. IN: COUDRY, M. I. H. Diário de Narciso: discurso e afasia. 1. ed. São Paulo: Martins Fontes, 1988.

FOUCAULT, M. A arqueologia do saber. Petrópolis: Vozes, 1969.

GARCÍA, L. N. Pobre Cerebro. Los efectos de la pobreza sobre el desarrollo cognitivo y emocional, y lo que la neurociencia puede hacer para prevenirlos. Cuadernos de Neuropsicología/Panamerican Journal of Neuropsychology, v. 10, n. 3, 2016.

LIPINA, S. J.; POSNER, M. I. The impact of poverty on the development of brain networks. Frontiers in human neuroscience, v. 6, 2012.

PATTO, M. H. S. Para uma Crítica da Razão Psicométrica. Psicol. USP, São Paulo, v.8, n. 1, p.4762, 1997. Disponível em: <http://www.scielo.br/scielo.php?script=sci_arttext\&pid=S0103$65641997000100004 \& \operatorname{lng}=$ en\&nrm=iso $>$. Acesso em: 11 de junho de $201 \overline{7}$.

NOVAES-PINTO, R. C. A contribuição do estudo discursivo para uma análise crítica das categorias clínicas. 1999. Tese (Doutorado em Linguística) - Instituto de Estudos da Linguagem, Universidade Estadual de Campinas, Campinas, SP, 1999.

NOVAES-PINTO, R. C. Linguagem, subjetividade e ensino: Reflexões à luz da neurolinguística discursiva. In: HARMUCH, R.A. SALEH, P.B.O. (org.) Identidade e subjetividade: Configurações contemporâneas, Campinas: Mercado de Letras, 2012, pp. 117-146. 
NOVAES-PINTO, R. C. Preconceito linguístico e exclusão social. Revista Avesso do Avesso 6(8). 8-36, 2008.

SHAYER, B. et al. Desempenho de escolares em atenção e funções executivas no Nepsy e inteligência. Psicol. teor. prat., São Paulo, v. 17, n. 1, pp. 120-135, abr. 2015. Disponível em: <http://pepsic. bvsalud.org/scielo.php?script=sci_arttext\&pid=S1516-36872015000100011\&lng=pt\&nrm=iso>. Acesso em: 11 de junho de $201 \overline{7}$.

UGÁ, V.D. A categoria "pobreza" nas formulações de política social do Banco Mundial. Rev. Sociol. Polit., Curitiba, 23, pp. 55-62, nov. 2004.

YAZBEK, M.C. Pobreza no Brasil contemporâneo e formas de seu enfrentamento, Serv. Soc. Soc., São Paulo, n. 110, pp. 288-322, abr./jun. 2012. 